\title{
As co-variatas políticas das mortes violentas
}

\author{
Gláucio Ary Dillon Soares \\ Instituto Universitário de Pesquisas do Rio de Janeiro \\ Centro de Estudos de Segurança e Cidadania \\ Universidade Candido Mendes
}

\begin{abstract}
Resumo
Os fenômenos do crime, da violência e do homicídio estão fortemente relacionados com fatores políticos, basta observar a incidência da violência policial e de Estado nas ditaduras e nos regimes totalitários ou o papel das políticas públicas e da sociedade civil democrática em coibi-los. Transformar regimes em variáveis é um dos passos fundamentais para se entender a evolução das taxas de mortes ou por causas externas nos países que passaram por mudanças de regimes políticos, como os países da Europa Oriental e do antigo bloco soviético. No caso latino-americano, não houve um quadro extremado de dissolução social semelhante mas, mesmo assim, experimentou-se uma diferença significativa nas taxas de homicídios antes e depois das transições políticas. Os dados relativos ao Brasil mostram a tendência de crescimento dessas taxas durante o regime militar e de estabilidade no período pós-transição democrática, o que rompe com uma visão que destaca o fenômeno inverso, uma espécie de onda de violência acompanhando o fim da ditadura militar.
\end{abstract}

Palavras-Chave: homicídios, violência, mudança política, democracia, Brasil.

\section{Abstract}

Crime, violence and homicide are strongly related to political factors, as we can see by the high incidence of police and state violence in dictatorships and totalitarisms or by the role of policy and democratic civil society in reduce them. Using regimes as variables is a fundamental step to understand the evolution of rates of violent deaths or by outside causes in countries that passed through political regime changes as in Eastern Europe and the former soviet bloc. In Latin America, there was no similar picture of extreme social dissolution but, nevertheless, had experienced a significative difference in homicide rates before and after political transitions. Data on Brazil show the tendence of growth of such rates in the military regime and of stability in the post-democratic transition period, what collides with the vision of thinking that occurs the opposite phenomenom, a kind of "wave of violence" following the end of the military dictatorship.

Keywords: homicide, violence, political change, democracy, Brazil. 
As variáveis políticas têm um papel importante no estudo do crime, da violência e do homicídio. Poucos percebem a relação entre democracia e violência, mas ela existe. Um tipo de violência que viceja nas ditaduras é a violência policial. A democracia, ao permitir a liberdade de imprensa, permite que se coloque a brutalidade na televisão, no rádio, no jornal.

\section{A democracia}

A democracia é um processo de longo prazo: se for mantida, os benefícios demoram, mas chegam. Uma das muitas áreas nas quais a democracia beneficia a população é o comportamento da polícia. A população brasileira tem uma relação ambígua com a polícia: precisa dela, mas a teme. Precisamente, teme a sua violência. Há uma relação negativa entre a democracia e a violência policial: quanto mais profunda e durável a primeira, menor a segunda. No imaginário popular, a violência policial é coisa de Terceiro Mundo. Dentro de limites, o imaginário bate com a realidade.

A mídia não é um espelho da realidade, uma apresentadora de estatísticas frias. Ela é mais sensível aos episódios extremos de violência policial letal do que ao acúmulo de episódios individuais do cotidiano. Chacinas com dez mortos têm mais espaço do que cem mortes individuais violentas por policiais. Não obstante, a mídia é indispensável para coibir a violência policial: ao aparecer na mídia, a violência força as autoridades responsáveis a algum tipo de ação. Muitas ações lentas, muitas ações com má vontade, mas são tomadas. $O$ efeito cumulativo de milhares dessas medidas aparece nas estatísticas. A Teoria das Janelas Quebradas, desenvolvida por Kelling e Wilson (1982), propõe que o astral de uma área urbana é profundamente influenciado por pequenos crimes e pequenas infrações, como as pichações, o barulho, as bebedeiras, as pessoas usando a rua como banheiro e dormitório etc. Acredito que o astral reflita também a existência de normalidade no governo, por um lado, e de vontade política democrática para com o bem público, pelo outro. A vontade política autoritária não serve porque a censura caminha de mãos dadas com ela. Não existe o papel co-ator da mídia. 
A violência policial letal deixa cadáveres, e cadáveres são difíceis de esconder. Eles aparecem e entram nas estatísticas de uma maneira ou de outra. No Brasil, parte significativa da violência policial letal engrossava uma categoria estatística: mortes com armas de fogo com intencionalidade desconhecida. É lá que muitos mortos pela polícia vão parar. Esta categoria foi criada para acomodar aqueles casos em que, genuinamente, não se conseguia saber se foi um acidente, se o morto se suicidou ou se foi assassinado com arma de fogo. Um país dotado de boa polícia científica reduz muito estes casos, pois uma perícia competente elimina muitas dúvidas. Infelizmente, a polícia científica ainda está engatinhando no Brasil, muitos policiais da velha guarda acham que "fazer a cena do crime" é coisa de filme policial americano.

A ilegitimidade dos governos de Figueiredo e Sarney, que não foram eleitos, assim como a sua imagem de incompetência e ineficiência geraram um astral "de janelas quebradas". Durante esses dois governos, o número de mortos com intencionalidade desconhecida cresceu assustadoramente: de 1.526, em 1979, a 4.595 em 1986. Em 1989, atingiu o nível mais alto, 5.480. A partir do impeachment de Collor, o país tem gozado de relativa normalidade institucional. A partir de então, o número de mortos "por armas de fogo, com intencionalidade indeterminada" decresceu todos os anos até 1997. Neste último ano, atingiu 1.511, total mais baixo do que o de 1979, a despeito do crescimento da população. Esses dados plotados em gráfico mostram o caráter curvilinear destas mortes inexplicadas entre 1979 e 1997. Um polinômio de segundo grau explica bem esta relação, produzindo um $\mathrm{R}^{2}$ substancial, de 0,70 . Houve, durante este período de decréscimo, episódios notórios de violência policial, inclusive chacinas e participação de policiais em atividades criminosas. Devido à deficiente preparação das nossas polícias, e ao caráter incompleto do controle político e social da violência policial, a violência e a criminalidade policiais continua a existir. Mesmo assim, em conjunto com a continuidade da normalidade democrática, houve evidentes progressos das polícias em vários estados, incluindo academias que estão produzindo policiais militares e civis competentes, re-treinamento dos mais antigos (que é mais difícil do que a formação de novos) e abertura para o mundo acadêmico com realização de pesquisas. Parte do decréscimo pode ser atribuída à melhoria da coleta e da codificação das estatísticas, mas seria difícil atribuir o crescimento em anos anteriores à piora das estatísticas.

Se o Brasil mantiver a normalidade democrática, recuperar um certo dinamismo na economia e enfrentar o sério problema da desigualdade e da exclusão, as inversões que estão sendo gradualmente feitas na melhoria das polícias continuarão a surtir efeito, e a triste e vergonhosa violência policial continuará a diminuir até o ponto no qual mereçamos o título de país civilizado. 
Efeitos das guerras e outras catástrofes de cunho político e militar

A relação entre as guerras e a taxa de homicídio é complexa. Há evidência que, em algumas sociedades, o pós-guerra caracteriza-se por taxas de homicídio mais altas. Yang e Lester, por exemplo, usaram a porcentagem do orçamento federal dos Estados Unidos dedicada a gastos com a defesa no período de 1933 1986. É um indicador discutível. A teoria que vincula a guerra ou, talvez com mais exatidão, o pós-guerra, passa por duas subteorias: a do deslocamento social, que significaria problemas de ajustamento - econômico, social e psicológico - e a teoria de que as armas seriam facilitadoras da violência, tanto homicida quanto suicida. $A$ teoria do deslocamento social foi postulada a partir da observação de países onde a guerra se efetuou, inclusive a Inglaterra durante a Segunda Guerra Mundial, que foi fortemente bombardeada, mas não invadida. Os Estados Unidos não tiveram guerra em seu território e o seu orçamento de defesa foi muito inchado pela Guerra Fria, o que não caracteriza nenhuma das duas subteorias. Não obstante, os autores encontraram uma correlação negativa entre os gastos totais com a defesa, e também da porcentagem dos gastos federais com a defesa, e as taxas de homicídio e de suicídio. Quanto maior o gasto, menores as taxas de homicídio e suicídio (YANG e LESTER, 1997). Os autores percebem esses resultados como apoio à teoria que haviam apresentado na direção que postulava uma relação positiva.

\section{As mudanças de regime político}

Em países que passaram por mudanças políticas profundas, há uma tendência natural a associar mudanças ocorridas na sociedade às mudanças no regime político. Em alguns casos, efetivamente, há mudanças estruturais que acompanham a mudança de regime. Em países com estabilidade e continuidade institucionais, esse tipo de explicação não se incorpora à teoria criminológica, exceto lateralmente, a partir da experiência dos que se dedicam a estudos comparativos e internacionais. Porém, em países que passaram há poucas décadas por importantes mudanças de regime, essa perspectiva está presente nas análises e explicações. Os estudos sobre a violência estão crescendo nos países ex-comunistas e a mudança de regime é parte da explicação.

Entre os que estudam o efeito das mudanças de regime sobre a sociedade, há os que enfatizam a mudança e os que enfatizam o regime. Não são apenas duas ênfases entre seguidores da mesma teoria, mas tipos diferentes de teoria. Os que enfatizam a mudança tocam em outras teorias, relacionadas com a desorganização 
social e o deslocamento social, levam em consideração a velocidade da mudança e importam conhecimento dos que pesquisam os efeitos das migrações e da urbanização acelerada, entre outros processos sociais. A explicação reside no processo.

Os que enfatizam o regime colocam maior ênfase nos aspectos políticos e instituticionais, trabalhando com categorias mais abrangentes, como democracia, comunismo e ditadura. Trabalham com políticas públicas, com o grau de organização da sociedade a partir do Estado e com prioridades sociais nas políticas públicas, ou, se for o caso, sua falta. A explicação começa no político.

As mudanças políticas radicais, de regime, incluem importantes mudanças radicais no consumo de bebidas alcoólicas, reduzindo-o. Os efeitos dessas mudanças só se tornaram conhecidos após o fim do socialismo, quando os dados se tornaram acessíveis aos pesquisadores. O que esses dados mostram é uma redução dramática nas taxas de mortalidade por homicídios, por suicídios e por acidentes.

Não obstante, há problemas metodológicos no meio: as mudanças de regime não significam apenas mudanças na sociedade, mas significam, também, mudança na forma, extensão e qualidade dos dados coletados e na transparência desses dados. Esta característica gera um problema adicional para o pesquisador: até que ponto as mudanças que encontram devem-se a mudanças no fenômeno e até que ponto devem-se a mudanças apenas na coleta dos dados e na sua transparência?

A história recente da humanidade permite acompanhar os efeitos da mudança de um regime comunista ossificado para um regime capitalista selvagem, criminoso. Seguindo os conselhos irresponsáveis de economistas acadêmicos que concederam à sua disciplina um status de ciência que ela não tem, os dirigentes dos países ex-comunistas, pressionados pelas potências democráticas, apressaram-se em fazer uma transição rápida. O resultado foi a transição que começou com a pilhagem de um regime e transformou-se num regime de pilhagem. O custo, em vidas humanas, foi alto e os economistas irresponsáveis não aceitam a responsabilidade por ele. 


\section{Aspectos espaciais da diminuição da esperança de vida na Rússia}

Walberg e outros perceberam que o aumento da mortalidade na Rússia, entre 1990 e 1994, não fora homogêneo. Decidiram estudar as variações espaciais entre subdivisões da Rússia européia, chamadas oblasts, deixando de fora a Sibéria e as regiões do Cáucaso mais afetadas pela guerra da Chechênia (WALBERG et al., 1998). Confirmaram que a queda na expectativa de vida tinha variado muito entre as oblasts. Além disso, rejeitaram a tese de que a queda dever-se-ia em grande parte à pobreza, porque algumas das regiões mais ricas estavam entre as mais afetadas.

A quê, então, atribuir o declínio? Uma das principais variáveis explicativas havia sido proposta por Cornia e Paniccia: mudanças no emprego. O indicador é a soma de ganhos e perdas no emprego das empresas médias e grandes como porcentagem do emprego total (os anos foram 1993 e 1994). Não é uma medida de desemprego, mas de mudança. Teoricamente, este conceito se encaixa como um dos custos da transição, associada com o choque no mercado de trabalho. Outros três fatores estão presentes e pesam na balança: a desigualdade na distribuição de renda, o crime e o consumo de álcool.

É interessante notar que o grosso do aumento da mortalidade não se deu entre jovens adultos, mas entre pessoas de trinta a sessenta anos. É interessante também que a queda na expectativa de vida não teve determinantes diferentes por gênero: o declínio entre os homens tinha uma alta correlação com o declínio entre as mulheres. As oblasts onde houve maior baixa na expectativa de vida masculina também tiveram maior baixa na expectativa de vida feminina.

A Rússia, como centro e origem do comunismo no poder, é um caso que deve ser estudado, mas algumas repúblicas menores também passaram por mudanças radicais que foram multiplicadas pela mudança de parte submissa, com autonomia limitada, de uma união dominada pela Rússia para uma república independente. Por disponibilidade de dados, usamos alguns países como a Estônia.

A primeira observação refere-se à deterioração generalizada das condições de vida, ao tremendo crescimento da desigualdade na distribuição de renda e ao desmantelamento das instituições de amparo social, com a resultante de que a mortalidade geral aumentou substancialmente e a esperança média de vida ao nascer diminuiu. Cornia e Paniccia argumentam que deterioração semelhante só pode ser observada, historicamente, durante guerras e fomes (CORNIA e PANICCIA, 1995). Efetivamente, foi uma redução na vida humana semelhante à observada durante grandes catástrofes naturais, guerras, pestes e fomes. 
É dentro desse panorama de deterioração das condições de vida e de aumento da mortalidade que o aumento dos homicídios tem sido colocado.

Vimos que a estabilidade nas taxas de homicídio é a norma. Na Rússia, as taxas de homicídio por cem mil, tanto masculinas quanto femininas, dobraram em dois anos, entre 1991 e 1993.

\section{Figura 1}

Evolução das taxas de homicídios na Rússia, por gênero, 1990 a 1994 (por cem mil habitantes)

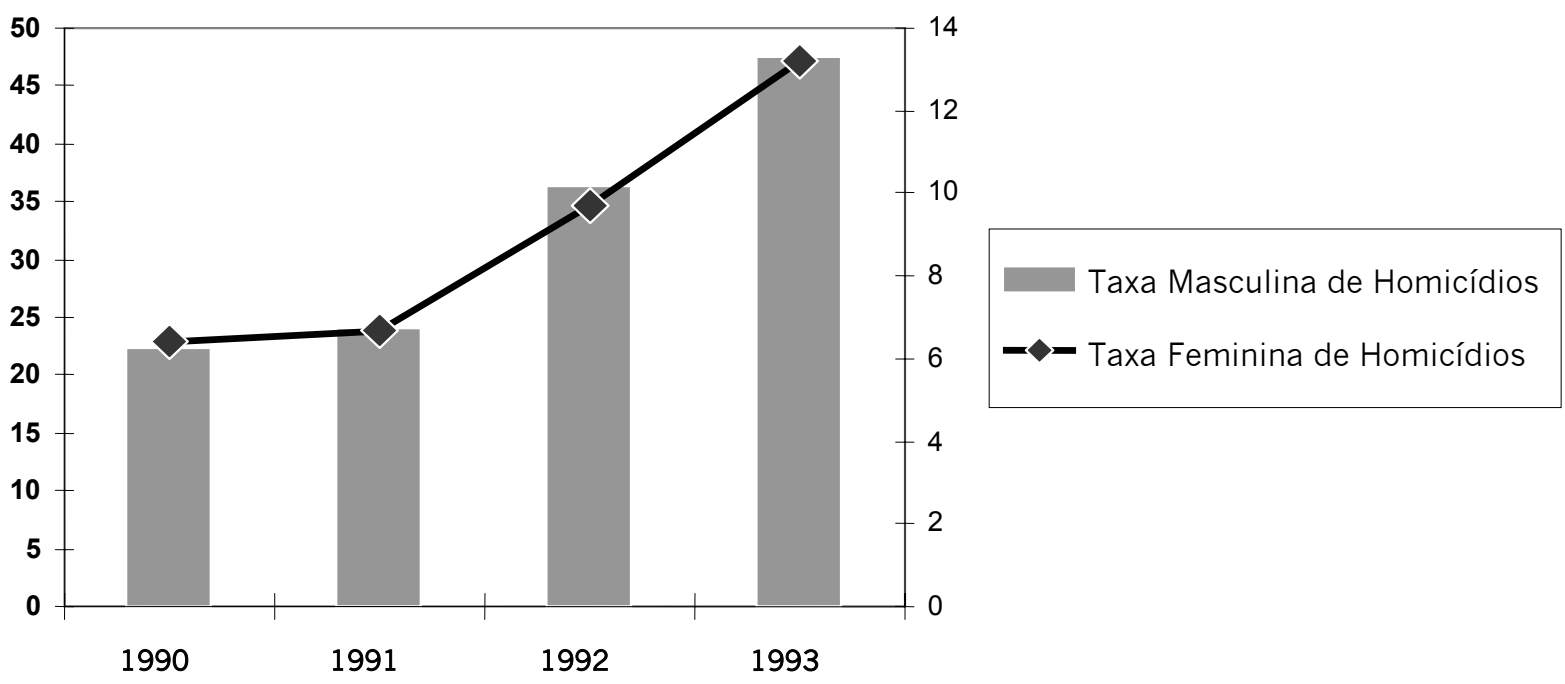

Nota: a taxa masculina refere-se ao eixo numerado da esquerda e a feminina ao da direita.

As duas taxas já haviam crescido entre 1990 e 1991, mas, entre 1991 e 1993, elas saltaram. É importante, para a escolha de uma perspectiva teórica adequada, demonstrar que esse não foi, apenas, um aumento da violência criminal, mas um crescimento de todos os índices negativos, que pode ocorrer quando um regime se desfaz sem ser substituído por outro. Tratava-se de um colapso político e social e não de um aumento isolado da violência. Vejamos o crescimento, rigorosamente semelhante, das taxas de suicídio: 
Figura 2

Evolução das taxas de suicídio na Rússia, por gênero, 1990 a 1994

(por cem mil habitantes)

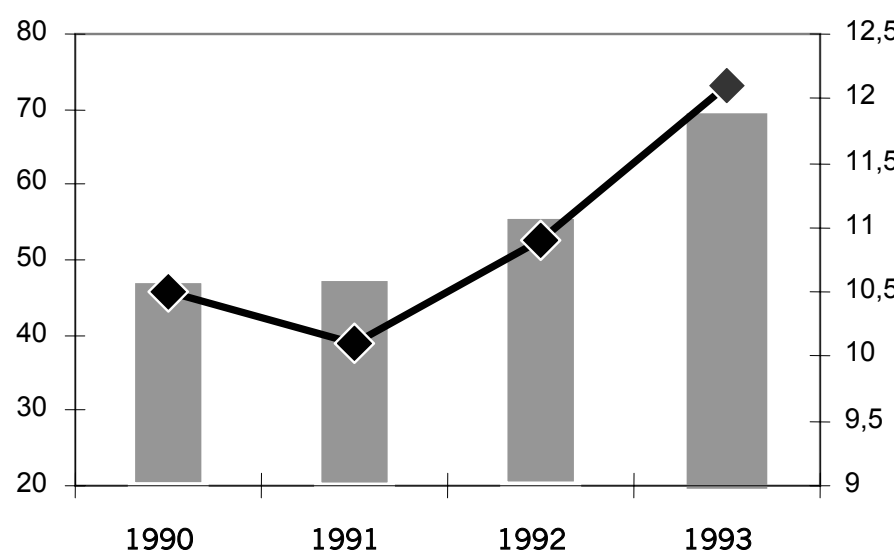

12

11,5

11

Taxa Masculina de Suicídios

10,5

- Taxa Feminina de Suicídios

10

9,5

Nota: a taxa masculina refere-se ao eixo numerado da esquerda e a feminina ao da direita.

O período caracterizou-se por um tremendo incremento de outras taxas de mortes externas, inclusive quedas, afogamentos, asfixias, eletrocuções etc ${ }^{1}$. Não obstante, em parte elas revelam o dramático crescimento do alcoolismo. 0 crescimento foi relativamente aumentado pelo contraste com a campanha antialcoolismo de Gorbachev, que muitos detestavam, mas que provocou um decréscimo sensível nas mortes por cirrose e outras doenças hepáticas crônicas ${ }^{2}$, além de um decréscimo muito maior nas outras taxas, referentes a acidentes de todo tipo e à violência, que estão intimamente relacionadas com o consumo de álcool e de outras drogas.

Após a mudança de regime, as taxas por cem mil habitantes de mortes por cirrose e outras doenças crônicas do fígado aumentaram de 1990 a 1994: 14,1; 15,1; 22,6 e 29,7. A relação com o fim das restrições ao consumo de álcool são óbvias. Porém, as mortes diretas, através de doenças hepáticas, são minoria quando comparadas com as mortes indiretas provocadas pelo alcoolismo e consumo de outras drogas. A mudança de regime foi sentida na sociedade pelo aumento do consumo de bebidas alcoólicas e, através deste aumento, pelo aumento nas taxas de mortes violentas de todo tipo. As "outras" causas externas foram numericamente mais importantes do que homicídios, suicídios e mortes no trânsito somados, crescendo vertiginosamente no período.

\footnotetext{
1 (E800-E807, E826-E949, E980-E999) na nona revisão da International Classification of Diseases.
}

2 (571.0.571.3, 571.5, 571.6) na nona revisão da International Classification of Diseases. 
Figura 3

Evolução das taxas de mortalidade por outras causas externas na Rússia, por gênero, 1990-1993

(por cem mil habitantes)

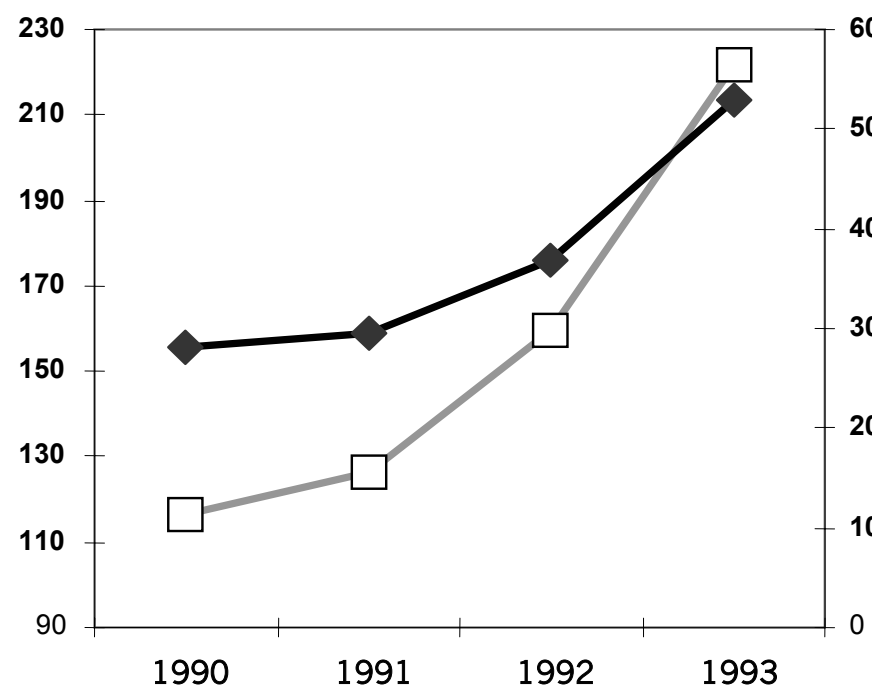

Nota: a taxa masculina refere-se ao eixo numerado da esquerda e a feminina ao da direita.

Em 1993, a taxa de todo o país era de 133 por cem mil habitantes, muito mais que a soma das taxas de homicídio $(29,7)$, suicídio (38) e acidentes de trânsito (25). O crescimento do alcoolismo reflete-se nessas mortes com números muito maiores do que de maneira direta, através das doenças hepáticas, que requerem a manutenção do vício durante um tempo grande. Além disso, repito que é possível que o colapso do Estado influencie o cuidado com a coleta de dados e o funcionamento da polícia, e não apenas a transparência, fazendo com que muitas mortes de origem mais difícil de identificar sejam simplesmente jogadas em categorias residuais. 
Outros países socialistas da antiga Europa Oriental seguiram trilhas semelhantes: Kaasic et al. (1988) compararam as taxas de mortalidade geral e por algumas causas específicas na Estônia e na Suécia entre 1990 e 1994. A esperança média de vida ao nascer dos homens e das mulheres aumentou gradualmente na Suécia, como vem ocorrendo em todos os países industrializados democráticos e sem profundas contradições raciais e sociais: de 74,8 a 76,1 anos, entre os homens, e de 80,4 a 81,4 anos, entre as mulheres. Já na Estônia, a esperança de vida dos homens baixou de 64,6 para 61,1, uma perda brutal de três anos e meio em apenas quatro anos e a das mulheres baixou de 74,6 para 73,1, uma perda de um ano e meio.

A taxa de vitimização por homicídios entre os homens saltou, na Estônia, de 19,2 por cem mil em 1990 para 46,7 em 1994; a das mulheres também mais do que dobrou, de 4,1 para 10. Mas não foi, apenas, um aumento da violência e do crime: a taxa de suicídio também saltou de 44,6 para 73 entre os homens; a das mulheres aumentou muito moderadamente, de 13,1 para 13,7. A taxa de mortes por intoxicação alcoólica, causadas tanto por um aumento do consumo quanto por uma baixa criminosa na qualidade das bebidas (tanto fabricadas internamente quanto importadas) também aumentou dramaticamente.

Figura 4

Taxas de Mortalidade por Causas Selecionadas na Estônia, 1990 e 1994 (por cem mil habitantes)

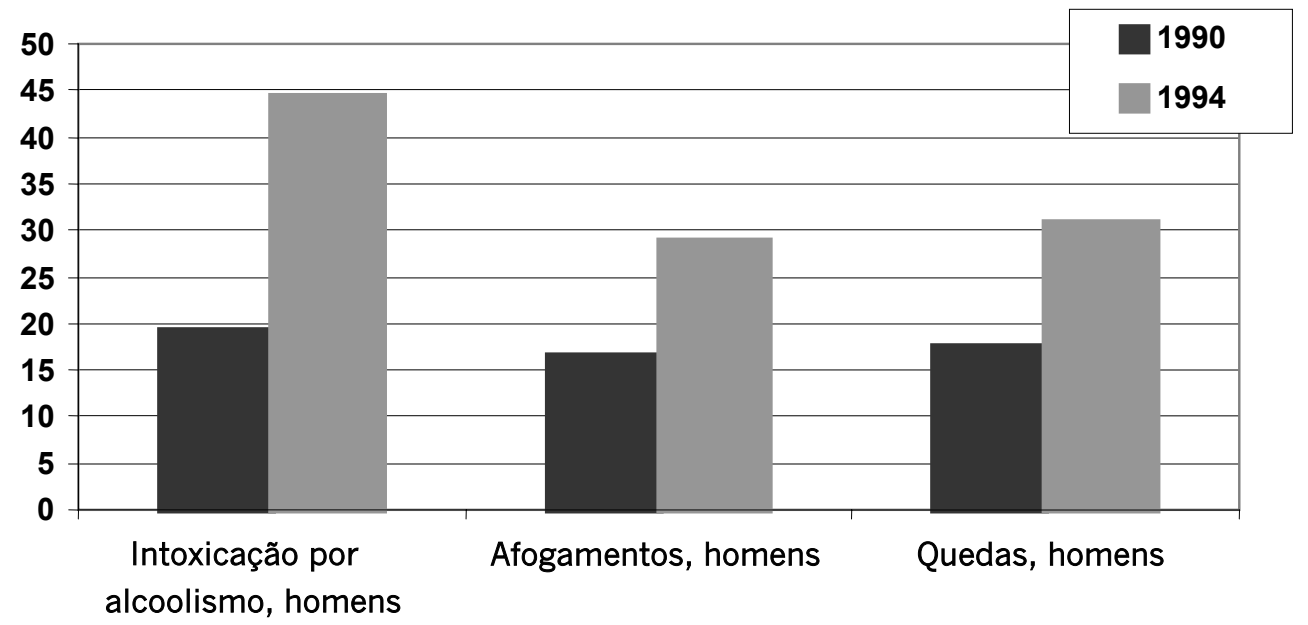


Os dados mostram o tremendo crescimento, entre os homens, das mortes por intoxicação alcoólica entre os estonianos de 1990 a 1994. Essa era uma população acostumada às seguranças mínimas de um Estado comunista, assim como às suas restrições e limites. Aceitando que havia (e há) corrupção nos Estados comunistas e que há enriquecimento pessoal dentro do aparelho do Estado, é um fenômeno diferente do que ocorre em Estados capitalistas, nos quais, além do enriquecimento pessoal igualmente ilegal através da corrupção, há o enriquecimento pessoal legal através da propriedade de bens de produção, no sentido amplo. O que se viu foi uma canibalização do Estado e um crescimento tremendo da desigualdade e, para a maioria (possivelmente mais de $80 \%$ da população), o breve sonho do enriquecimento capitalista seguido do pesadelo da pobreza capitalista e de um capitalismo que se desfazia do seu passado comunista e, com ele, das instituições de proteção social.

O problema do álcool nas repúblicas bálticas (Estônia, Lituânia e Látvia) mereceu estudo à parte (McKEE et al., 2000). O problema é sério: metade dos homens e um sexto das mulheres admitiram que bebiam pelo menos uma vez por semana. As correlatas do consumo eram a idade e a renda. Na Estônia, havia diferenças entre os grupos étnicos, com os russos bebendo menos.

O problema também foi estudado por um dos principais epidemiólogos da Europa Oriental, Chenet, que, com seus associados, analisou a contribuição de binge drinking para as variações nas mortalidade na Lituânia. Essa expressão referese ao hábito de beber muito de cada vez, ainda que possivelmente não tantas vezes quanto um consumidor de vinho. É hábito arraigado em alguns países, inclusive na Lituânia e na Rússia (CHENET et al., 2001).

A influência nefasta do consumo de álcool foi sentida em outras repúblicas do antigo sistema socialista. Na Romênia, entre 1990 e 1996, houve uma redução de 1,71 anos de vida entre os homens e de 0,54 entre as mulheres. 0 aumento da mortalidade deveu-se a doenças cardiovasculares e do sistema digestivo, e à cirrose, em particular entre adultos e idosos (DOLEA et al., 2002).

A Geórgia é um caso à parte porque os dados são muito pobres e porque ela não seguiu o padrão das repúblicas da antiga URSS. Para começar, um quinto do país está fora do controle do governo; além disso, houve fortes movimentos migratórios a partir de 1991. Badurashvili e outros usaram instrumentos demográficos para acessar as mudanças na expectativa de vida na Geórgia durante e após "a transição" (BADURASHVILI et al., 2001). A Geórgia é uma exceção em todos os sentidos: não foi muito beneficiada pela política de restrição ao consumo de álcool imposta por Gorbachev em 1985 nem foi tão afetada pela transição quanto outras repúblicas soviéticas. 
A Alemanha Oriental e a Polônia apresentam um perfil diferente. Houve uma perda de um ano durante a transição e uma recuperação logo após. A perda, de aproximadamente um ano na esperança de vida ao nascer dos homens, foi em parte devida a causas externas - homicídios, acidentes e suicídios. O declínio entre as mulheres também foi menos pronunciado: 0,3 ano. Estas perdas foram mais do que compensadas pelo crescimento rápido após a transição inicial: entre 1991/92 e 1996/97 a esperança de vida ao nascer entre os homens aumentou 2,4 anos na Alemanha Oriental e 2 anos na Polônia (NOLTE, SHKOLNIKOV e McKEE, 2000). O caminho foi semelhante ao de outros países do antigo bloco socialista, mas os números foram muito mais favoráveis.

O crescimento do crime em geral, e da violência em particular, nos países do antigo bloco soviético não obedece às mesmas explicações que nos regimes capitalistas tradicionais. Ele acompanha o colapso de um sistema. Por isso, cresce juntamente com outros indicadores do colapso: o crescimento do consumo de drogas, particularmente do álcool; o crescimento das mortes por intoxicação alcoólica (agravado, no caso da Estônia, pela venda de produtos com alta taxa de letalidade); o crescimento dos afogamentos, das quedas e de outras mortes acidentais (mas não necessariamente no trânsito, devido à crise econômica que afetou a milhagem rodada), o crescimento das mortes por cirrose e outras disfunções hepáticas e o crescimento dos suicídios. O crescimento dos homicídios não foi um fenômeno isolado: foi parte de um quadro de dissolução social.

Martin McKee e Vladimir Shkolnikov (2001) fizeram um excelente estudo comparativo das mortes prematuras masculinas na Europa Oriental. Afirmam que, em 1990, a probabilidade de morte antes de 65 anos na União Soviética era o dobro da Europa Ocidental e, nos países comunistas da Europa Central e Oriental era $70 \%$ mais alta. Os autores sumarizam os resultados em vários pontos, dos quais sublinho alguns:

- As maiores causas da alta mortalidade eram a violência e as doenças cardiovasculares;

- Os altos níveis de consumo de álcool, principalmente o consumo por binges, foram causas importantes. O fumo e a má nutrição também tiveram um papel importante;

- Os homens que experimentaram mais mudanças ocupacionais e econômicas, os com menos educação e os com menos apoio social foram mais afetados e morreram mais cedo. 
Porém, Mckee e Shkolnikov trazem à baila o papel da centralidde das políticas públicas no que concerne às mortes violentas. Na visão dos autores, as autoridades dos antigos países socialistas e, depois do colapso, os governos seguintes, não deram importância às mortes violentas. Em 1997, a taxa de "mortes por causas externas", por cem mil homens com menos de 65 anos, era cinco vezes mais alta nos países da antiga União Soviética do que na Europa Ocidental; nos países da Europa Central e Oriental a taxa correspondente era o dobro da taxa na Europa Ocidental. São diferenças impressionantes. Todas as mortes por causas externas eram mais altas: as taxas de mortes no trânsito eram 50\% mais altas, as por suicídio eram quase três vezes e meia mais altas e as taxas por homicídio eram dezenove vezes mais altas. Outros acidentes, como afogamentos e mortes por fogo, também eram bem mais freqüentes.

O antigo bloco soviético, que já era diferenciado, diferenciou-se ainda mais durante e depois da transição. As repúblicas que faziam parte da União Soviética apresentavam e apresentam taxas substancialmente mais altas; alguns países como a República Checa e a Polônia, assim como a antiga Alemanha Oriental, tiveram fortes melhorias, em contraste, por exemplo, com a Bulgária e a Romênia, que não tiveram.

Os autores, como tantos outros, enfatizam a influência negativa do alcoolismo. Sublinham que a distribuição espacial das mortes por causas externas é quase idêntica à das mortes por envenenamento alcoólico. Chegam a afirmar que muitos homens que se suicidam estavam alcoolizados e que, nos homicídios, ou a vítima ou o algoz, ou os dois, estavam ébrios.

A transição do comunismo para o capitalismo é certamente diferente da mudança de regime mais recente observada na maioria dos países latinoamericanos que passaram de uma ditadura militar para uma democracia. Nesta transição, a mudança foi menor. A mudança foi essencialmente política, o sistema econômico e social não foi desmantelado. Em alguns casos, a política econômica do regime militar não foi abandonada - ao contrário, foi mantida ou aprofundada. Não houve ruptura. Socialmente, várias das novas democracias introduziram modestas alterações nas políticas altamente concentradoras e investiram apenas marginalmente em políticas sociais. Ainda que modestas e, em alguns casos, pequenas, essas mudanças tiveram conseqüências positivas. Em outra direção, as políticas públicas em relação ao alcoolismo e às drogas e ao porte de armas chegaram tarde nas democracias latino-americanas. A crítica de McKee e Shkolnikov (2001) também se aplica à América Latina. 
Outro exemplo da influência de fatores políticos sobre o comportamento humano violento talvez resida na Hungria. Em meados da década de 1950 a Hungria tentou se distanciar do tipo rígido de comunismo da União Soviética, iniciando uma tentativa de democratização. Falava-se, outra vez, no socialismo democrático, na democracia dentro do socialismo. Foi um momento de esperança, ainda que breve. A explosão democrática húngara foi massacrada pelos tanques do Pacto de Varsóvia e a abertura foi interrompida. A Hungria voltou à órbita soviética. Não disponho de dados de longo prazo sobre o homicídio na Hungria, mas os tenho sobre o suicídio. O efeito esperado seria o crescimento posterior. Houve, efetivamente, um crescimento rápido das taxas de suicídio por cem mil habitantes:

Figura 5

Evolução das taxas de suicídios na Hungria, 1881 a 1988 (por cem mil habitantes)

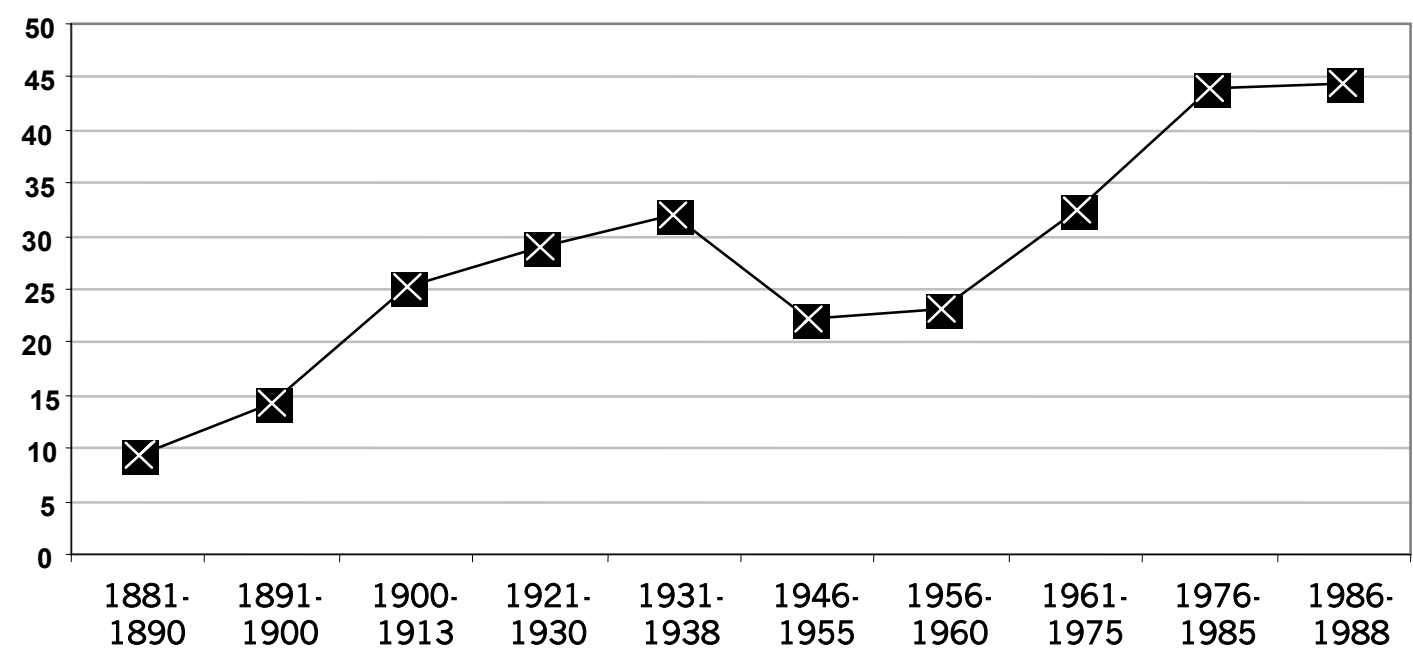

Os dados mostram que a taxa de suicídios cresceu na Hungria de 1881/90 ao início da Segunda Guerra Mundial, decrescendo até 1946/55. Em 1956, houve a invasão pelas tropas do Pacto de Varsóvia e, durante as três décadas seguintes, pelo menos, a taxa cresceu perto de vinte pontos, dobrando. 
Portanto, os dados disponíveis apóiam a hipótese de que as taxas de vários comportamentos, como o homicídio e o suicídio, podem acompanhar mudanças de regime. As mudanças de regime não são fenômenos cotidianos, mas elas repetem. se historicamente, sendo relativamente freqüentes. As mudanças que acarretam raramente têm a magnitude das observadas na transição do ex-bloco soviético. Não obstante, elas necessitam ser incorporadas às teorias do homicídio pois, sem elas, o crescimento rápido do homicídio cum crescimento rápido de outros indicadores de desintegração social fica sem explicação. Mas essa transição tem que ir além da explicação cabalística do "fim do socialismo" e analisar quais as políticas públicas associadas ao crescimento de taxas específicas.

\section{A taxa de homicídios e a mudança de regimes no Brasil}

O fato de o Brasil ter estado vinte e um anos em um regime militar e ditatorial e ter passado a um regime democrático se oferece como explicação para uma série de comportamentos, inclusive os relacionados com o crime e a violência.

A idéia (falsa) de que existe uma "onda" de violência, caracterizada por um crescimento de assaltos, latrocínios e homicídios a curto prazo - leia-se um ou dois anos - levou alguns defensores de regimes autoritários a vincular a "onda" de violência ao fim do regime militar e, segundo os mais extremados e menos instruídos, com a "bagunça democrática".

Várias pesquisas demonstram a falsidade empírica dessa pseudo. explicação. Barata et al. (1999) apresentam dados que mostram que, para o conjunto dos homicídios, o período de maior crescimento foi o de 1979 a 1984 . O gráfico, com barras de erros, para as taxas de homicídios masculinos por cem mil habitantes, que aqueles autores construíram mostra isso visualmente: 
Figura 6

Evolução nas taxas masculinas de homicídios na cidade de São Paulo, Brasil

1979 a 1994

(por cem mil habitantes)

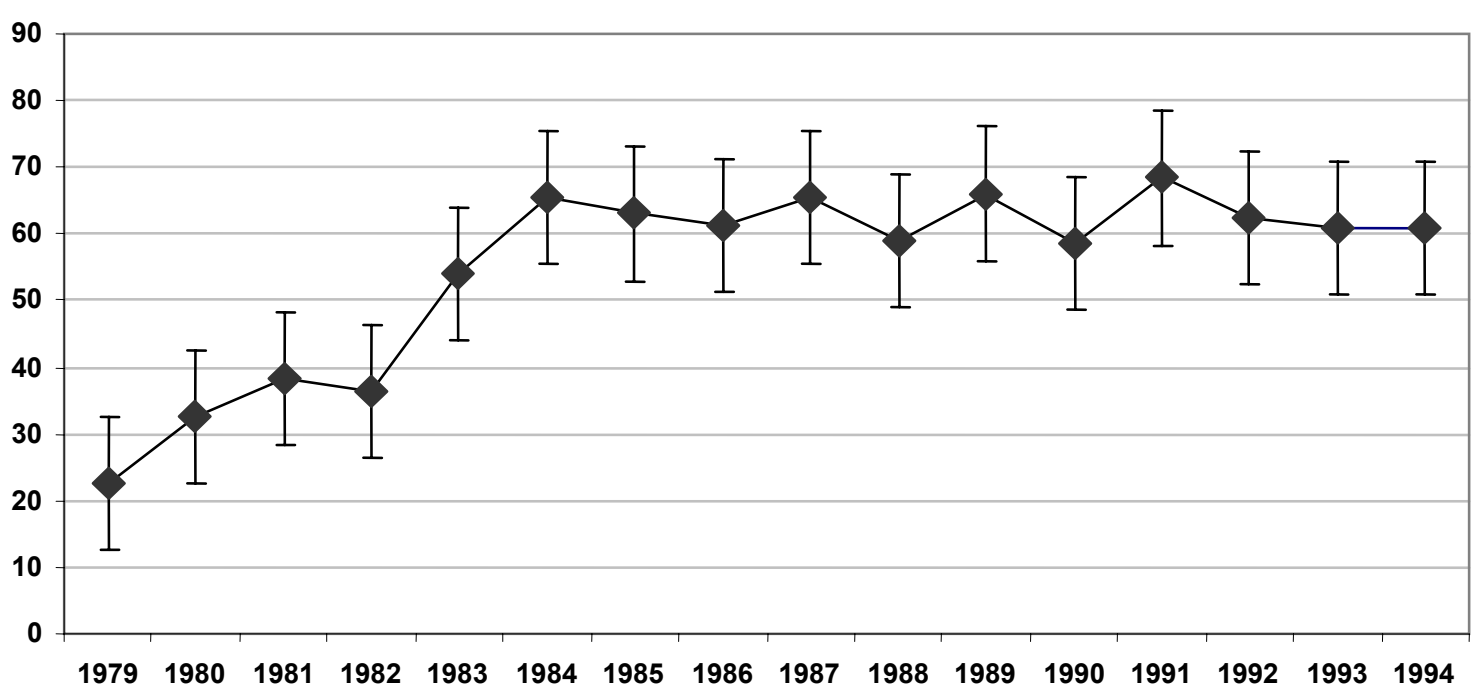

Houve rápido crescimento entre 1979 e 1981, pequeno decréscimo em 1982, ano em que se anunciou a crise "da dívida", tremenda aceleração de 1982 a 1984, a ponto de justificar a afirmação de que teria havido uma "onda" de homicídios, com o problema teórico adicional de que, a partir daí, não houve crescimento significativo; a taxa de 1994 foi inferior à de 1984.

Fazendo a partição dos dados de acordo com o regime político, de 1979 a 1985 e de 1986 a 1994, vemos que o período relativo ao regime militar caracterizou-se por um claro crescimento e que a regressão linear simples, sem correção $(y=7,2593 x+15,556)$, proporciona uma solução que indica que a taxa de homicídios crescia a mais de sete ao ano (sete por mil é, aproximadamente, a taxa americana em 2000). Ou seja, a taxa masculina de homicídios por cem mil habitantes na cidade de São Paulo cresceu, cada ano, durante os últimos tempos do regime militar, o equivalente à taxa americana de um ano. $O \mathrm{R}^{2}=0,92$, indica a previsibilidade do fenômeno conhecendo as taxas dos anos anteriores. 
Figura 7

Evolução das taxas masculinas de homicídios na cidade de São Paulo, Brasil

Período final da ditadura - 1979 a 1985

(por cem mil habitantes)

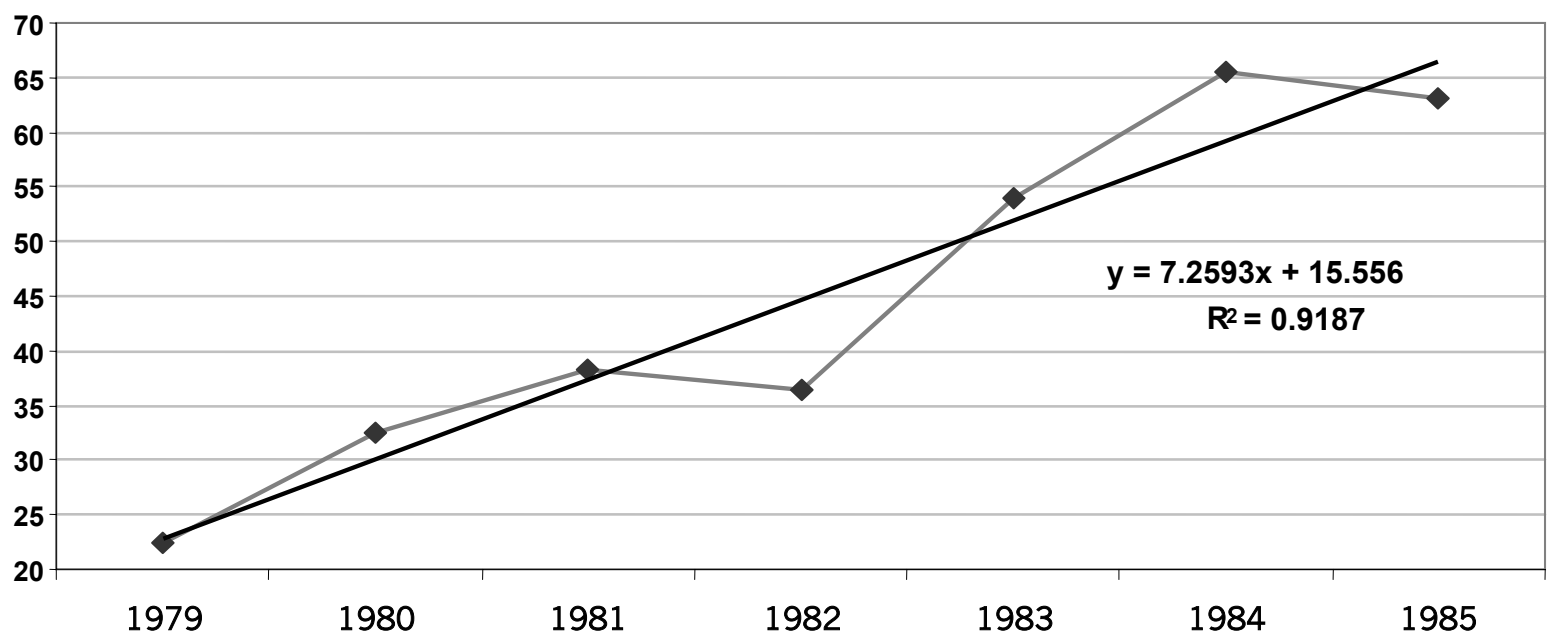

Para os que costumam buscar "ondas" de crime e de violência, esse período talvez tenha sido o que mais se aproximou do crescimento que o conceito de onda induz: as taxas por cem mil habitantes cresceram de pouco mais de vinte e dois a quase sessenta e seis por cem mil habitantes em seis anos, quase triplicando. Entretanto, diferente do conceito de onda, que acaba, e as taxas diminuem, a violência continuou no mesmo patamar em que foi deixada pelo regime militar.

A regressão linear para o período de 1986 a 1994 não produz resultados consistentes. Visualmente, houve estabilização, com variações relativamente pequenas de ano a ano. $O$ coeficiente é negativo e o coeficiente de determinação $R^{2}$ $=0,005$, que não é estatisticamente significativo. Conhecer as taxas dos anos anteriores à democratização não ajuda a conhecer a taxa dos anos seguintes: a inspeção visual do período democrático mostra estabilidade com variações, sem tendência definida ao crescimento ou à diminuição.

Os autores deste excelente estudo (BARATA et al., 1999), efetuando a partição dos dados por sexo e por idade, puderam chegar a resultados mais específicos: 
Entre as mulheres:

- Durante o regime militar, cresceram as taxas nas faixas dos 10 aos 39 anos, ao passo que, nas demais faixas etárias, as taxas de vitimização por homicídio tiveram pequenas variações;

- A partir da redemocratização, houve estabilização ou queda entre todos os grupos etários.

Entre os homens:

- Durante o regime militar, cresceram as taxas em todas as faixas entre 10 e 59 anos;

- Durante o regime democrático, continuaram a crescer as taxas masculinas de adolescentes e jovens adultos, particularmente entre 20 e 29 anos; na faixa dos 30 a 39, variaram pouco, sem direção; decaíram um pouco na faixa de 40 a 49; decaíram bastante nas faixas de 50 a 59, 60 a 69 e 70 anos e mais.

Minha conclusão é que aumentou a desigualdade entre as idades nas taxas de vitimização, tanto entre homens como entre mulheres.

Figura 8

Evolução das taxas masculinas de homicídios na cidade de São Paulo, Brasil

Períodos de implantação e consolidação da democracia, 1986 a 1994 (por cem mil habitantes)

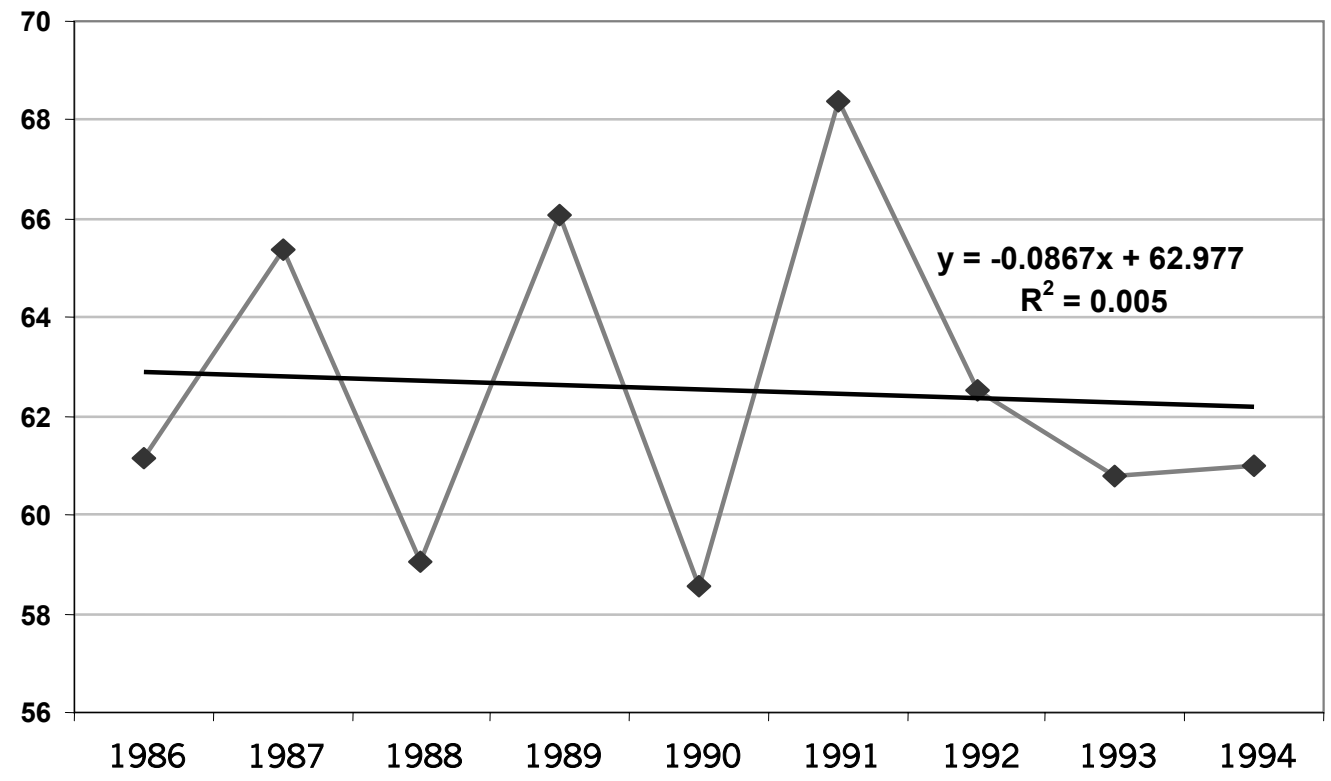


Fica, portanto, claro, graças ao cuidadoso estudo de Barata et al., que o período de grande crescimento da taxa de homicídios foi entre 1979 e 1985, mas que grupos etários e os sexos não tiveram comportamento semelhante. A partir de 1985 até 1994, houve pequenos zigue-zagues, mas a tendência maior foi a estabilização das taxas de homicídio nos altos níveis em que foram deixadas pelo regime militar. Na cidade de São Paulo, o regime democrático impediu que as taxas continuassem crescendo, mas não as diminuiu.

Essas tendências têm certa semelhança com as encontradas em outras áreas metropolitanas brasileiras, como demonstrado por pesquisadores como Ignácio Cano, Leandro Piquet Carneiro e Edmundo Campos, entre outros. Cabe, portanto, a pergunta: se os dados mostram claramente que o crescimento maior da taxa de homicídios ocorreu dentro do regime militar nos seus últimos anos, porque ainda há quem creia que o crescimento se deu depois? Na minha opinião, a resposta passa por alguns níveis:

- Os poucos estudos quantitativos, mais precisos, são posteriores ao fim do regime militar;

- Havia censura durante o regime militar e a violência do mesmo afetou negativamente muitos pesquisadores que se abstiveram de publicar trabalhos cujas conclusões fossem críticas ao regime;

- A preocupação social com a violência cresceu depois do fim do regime militar, a sociedade abriu os olhos para a violência civil;

- A ausência de dados - os dados não eram facilmente acessíveis e muitos militares e burocratas consideravam os dados de segurança pública como assunto de segurança nacional - impedia o trabalho de pesquisa quantitativa;

- A inexistência de dados confiáveis trabalhados e publicados permite uma sobrevida às teorias e pseudo-teorias que não resistem ao confronto com esses dados;

- As teorias em voga no Brasil não são criminológicas, mas teorias da sociedade e da economia indevidamente esticadas para incluir o crime e a violência.

Determinar que as mudanças de regime político têm conseqüências para o comportamento violento, particularmente o homicídio, significa que devemos integrar esse conhecimento nas teorias com que trabalhamos. O que fizemos foi demonstrar que estas mudanças afetam as taxas, aumentando-as ou diminuindo-as. Não obstante, é provável que o regime político interaja com outras variáveis, cuja relação com o homicídio seria significativamente mais diferente em um regime do que em outro. Mais do que isso, ela seria diferente nas mudanças de regime. Isso 
significa que qualquer conjunto de hipóteses, qualquer teoria, que comece e termine dentro de um regime é necessariamente incompleta e talvez não se aplique, ou tenha uma aplicação mais modesta, em regimes diferentes ou em mudanças e transições. Trabalhar com dados limitados a um regime impede conhecer a influência do próprio nome dentro do qual se trabalha. A virtude dos estudos comparativos e históricos é transformar os regimes em variáveis, o que permite visualizar o seu efeito sobre o crime, a violência e o homicídio.

\section{Referências Bibliográficas}

BADURASHVILI, I.; McKEE, M.; TSULADZE, G.; MESLE, F.; VALLIN, J.; SHKOLNIKOV, V. Where there are no data: what has happened to life expectancy in Georgia since 1990?. Public Health, v. 115, n. 6, p. 394-400, November, 2001.

BARATA, R. B.; RIBEIRO, M. C. S. de A.; MORAES, J. C. de. Tendência temporal da mortalidade por homicídios na cidade de São Paulo, Brasil, 1979-1994. Cadernos de Saúde Pública, v. 15, n. 4, Out/Dez, 1999.

CHENET, L.; BRITTON, A.; KALEDIENE, R.; PETRAUSKIENE, J. Daily variations in deaths in Lithuania: the possible contribution of binge drinking. International Journal of Epidemiology, v. 30, n. 4, p. 743 - 748, August, 2001.

CORNIA, G. A.; PANICCIA, R. The demographic impact of sudden impoverishment: Eastern Europe during the 1989-1994 transition. Innocenti Occasional Papers, Economic Policy Series, UNICEF International Child Development Centre, Florence, v. 49, 1995.

DOLEA, C.; NOLTE, E.; McKEE, M. Changing life expectancy in Romania after the transition. Journal of Epidemiology and Community Health, v. 56, n. 6, p. 444-449, June, 2002.

KAASIK, T.; ANDERSSON, R.; HÖRTE, L. The effects of political and economic transitions on health and safety in Estonia: an estonian-swedish comparative study. Social Science and Medicine, v. 47, n. 10, p. 1589-1599, 1998.

MCKEE, M.; SHKOLNIKOV, V. Understanding the toll of premature death among men in Eastern Europe. British Medical Journal, v. 323, 3 november 2001.

McKEE, M.; POMERLEAU, J.; ROBERTSON, A.; PUDULE, I.; GRINBERGA, D.; KADZIAUSKIENE, K.; ABARAVICIUS, A.; VAASK, S. Alcohol consumption in the Baltic Republics. Journal of Epidemiology and Community Health, v. 54, p. 361-366, May, 2000. 
NOLTE, E.; SHKOLNIKOV, V.; McKEE, M. Changing mortality patterns in East and West Germany and Poland. II: short-term trends during transition and in the 1990s. Journal of Epidemiology and Community Health, v. 54, n. 12, p. 899-906, Dec, 2000.

WALBERG, P.; McKEE, M.; SHKOLNIKOV, V.; CHENET, L.; LEON, D. A. Economic change, crime, and mortality crisis in Russia: regional analysis. British Medical Journal, v. 317, p. 312-318, 1 August, 1998.

WILSON, J.; KELLING, G. Broken windows: the police and neighborhood safety. The Atlantic Monthly, 1982.

YANG, B.; LESTER, D. War and rates of personal violence. Journal of Social Psychology, v. 137, n. 1, p. 131-132, Feb, 1997. 